\title{
Changes In Suicide Rates Following Media Reports On Celebrity Suicide: A Meta- Analysis.
}

Word Count (main text only): 2865.

\section{Authors and Affiliations}

Thomas Niederkrotenthaler, ${ }^{1}$ King-wa Fu, ${ }^{2}$ Paul Yip, ${ }^{3,6}$ Daniel YT Fong, ${ }^{4}$ Steven Stack, ${ }^{5}$ Qijin Cheng, ${ }^{6}$ Jane Pirkis, ${ }^{7}$

${ }^{1}$ Department of General Practice and Family Medicine, Center for Public Health, Medical University of Vienna, Austria; E-mail:

thomas.niederkrotenthaler@meduniwien.ac.at

${ }^{2}$ Journalism and Media Studies Centre, The University of Hong Kong, Hong Kong; EMail: kwfu@hku.hk

${ }^{3}$ Centre for Suicide Research and Prevention, The University of Hong Kong, Hong Kong; E-Mail: sfpyip@hku.hk

${ }^{4}$ School of Nursing, Li Ka Shing Faculty of Medicine, The University of Hong Kong; EMail: dytfong@hku.hk

${ }^{5}$ Department of Psychiatry \& Department of Criminology, Wayne State University, Detroit, MI 48098 USA; E-Mail: aa1051@wayne.edu 
${ }^{6}$ Department of Social Work and Social Administration, The University of Hong Kong, Hong Kong SAR, PR China; E-mail: chengqj@hku.hk

${ }^{7}$ Centre for Health Policy, Programs and Economics, Melbourne School of Population Health, University of Melbourne, Australia; E-Mail: j.pirkis@unimelb.edu.au

\section{Corresponding author:}

Thomas Niederkrotenthaler

Department of General Practice and Family Medicine, Center for Public Health, Medical University of Vienna. Severingasse 9, A-1090 Vienna, Austria.

Phone: +43140160 34957; Fax: +43 40160934950

E-mail: thomas.niederkrotenthaler@meduniwien.ac.at

Keywords: Suicide, Mass Media, Famous Persons, Meta-Analysis. 


\section{ABSTRACT}

\section{Background}

A growing number of studies indicate that sensationalist reporting of suicide is associated with increases in suicide rates, but in the light of some negative findings the issue has remained controversial. The aim of this study was to evaluate the best current evidence on the association between celebrity suicide stories and subsequent suicides.

\section{Methods}

Literature searches of six data sources (Medline, Psychlit, Communication Abstracts, ERIC, Dissertation Abstracts and APAIS) were conducted. Studies were included if they: (a) adopted an ecological design; (b) focused on celebrity suicide; (c) had completed suicide as outcome variable; (d) analyzed suicide rates across all suicide methods; (e) used data from after the World War II; and (f) satisfied basic quality criteria.

\section{Results}

Ten studies met the criteria. The pooled estimate indicated a change in suicide rates (suicides/100,000 population) of $0.26(95 \% \mathrm{Cl} 0.09-0.43)$ in the month after a celebrity suicide. There was substantial heterogeneity between studies, which was explained by the type of celebrity (entertainment elite versus others) and the region of study, as indicated by mixed-effects meta-regression. The region-of-study specific effect of 
reporting a suicide by an entertainment celebrity was $0.64(95 \% \mathrm{Cl} 0.55-0.73)$ in North America, $0.58(95 \% \mathrm{Cl} 0.47-0.68)$ in Asia, $0.36(95 \% \mathrm{Cl}-0.10-0.61)$ in Australia and 0.68 (95\% Cl $0.51-0.85)$ in Europe. There was no indication of publication bias.

\section{Conclusion}

Reports on celebrity suicide are associated with increases in suicides. Study region and celebrity type appear to have an impact on the effect size. 


\section{INTRODUCTION}

Suicide is a major public health problem worldwide, accounting for approximately one million deaths each year.[1] In spite of major advances in recent years, gaps remain in knowledge about risk and protective factors related to suicidal behaviour.[1,2] Suicide seems to be a phenomenon that is susceptible to copycat behaviour, and there is a considerable body of literature which suggests that media reporting of suicide may lead to copycat acts.[3-10] Most frequently, copycat behaviour following media reports of suicide has been explained by social learning theory. Vulnerable individuals (for example those in psycho-social crisis) may learn that suicide is an acceptable solution to personal problems from media broadcasts and consequently adopt suicidal behaviour.[11]

Reporting of celebrity suicides has been at the core of scientific interest and of preventive endeavors in recent years. $[7,9,12-17]$ These suicides are extensively covered in the mass media and are of special concern because the celebrities are revered and may therefore act as particularly strong role models.[7,17] Numerous guidelines for reporting on suicide have been prepared by national public health institutions and international organisations (e.g., the World Health Organization). All of them acknowledge that there will be considerable public interest in a report of a celebrity's suicide and recommend that reports of these deaths should be sensitive and nonsensationalist.[17] 
Despite this, debate continues about the actual impact of suicide reporting on suicide rates. $[5,18,19]$ There are several narrative reviews available which indicate a substantial heterogeneity with regard to individual study findings, including some negative findings. [4,5,18-21] To date, no systematic meta-analysis has been conducted in which estimates have been provided on the cumulative effect size related to copycat behaviour.

The current meta-analysis was conducted with a view to filling this gap. It systematically identified and brought together the findings from relevant studies. Studies dedicated to the effects of media reporting on suicide can generally be classified into: (a) descriptive studies (i.e., studies of individual cases or a group of individuals with no comparator); and (b) analytical studies (i.e., studies involving a comparison with another group).[4,20] The analytical studies can be further divided into: (a) individual-level; and (b) ecological studies. The vast majority of analytical studies in this area have been ecological studies, and have analyzed the possible effects of media reporting on aggregated suicide rates, using ecological before-and-after designs. These studies are generally of low specifity (i.e., cannot demonstrate that those individuals who subsequently died by suicide were exposed to the media stimulus).[4,20] Some individual-level studies have been conducted in this area.[4] In these studies, the outcome variable is typically a selfreported attitude towards suicide or a likelihood of suicidal behaviour. These studies overcome the problem of low specifity, but are not appropriate for examining the most important outcome of interest, which is completed suicide.[4] For this reason, the current review is limited to ecological studies. The Oxford Centre of Evidence based Medicine classifies well-conducted ecological studies as only Level II studies, indicating that evidence from these types of studies is generally lower than that from well-conducted 
randomized clinical trials (RCTs) and cohort studies.[22] Practical and ethical considerations make it almost impossible to conduct RCTs and cohort studies in this area. These higher level studies are almost impossible to conduct in this area. For these reasons, we aimed to systematically review the available ecological studies in order to evaluate the best current evidence on the association between reporting of celebrity suicides and suicide rates. 


\section{METHODS}

\section{Search strategy}

Two of our authors (TN and JP) conducted searches of Medline, Psychlit, Communication Abstracts, Education Resources Information Center (ERIC), Dissertation Abstracts and Australian Public Affairs Database (APAIS) from their respective years of inception to January 2011 to identify studies on the association between media reporting and actual suicidal behaviour.[4,20] We used the following search elements to identify relevant English-language articles: Suicide (suicid ${ }^{\star}$ ); Imitation (Werther; copycat; imitat*; contagio*); or Media (media; newspaper*; radio*; televis*; film*; movie*; book*; play*).[4] We screened titles and abstracts of retrieved articles, and obtained full text versions of articles reporting on studies that appeared to be relevant. We screened the reference lists of all retrieved articles for further potential articles. Efforts were also made to discover unpublished articles of relevance. We entered the above search terms into Google to to indentify any unpublished studies via the Internet. In addition, sought unpublished data through our informal networks, most notably the members of the International Association for Suicide Prevention's Suicide and the Media Task Force. A review protocol is available at http://www.mindframe-

media.info/client images/900016.pdf.[20]

\section{Study selection}


Studies were eligible if:(a) they adopted an ecological design comparing two or more time-points before and after a suicide broadcast in the same population; (b) they focused on media reporting of celebrity suicide; (c) they had completed suicide as an outcome variable; (d) they analyzed suicide rates across all suicide methods (deemed important because the evidence suggests that reports of suicide likely to have method-specific effects on suicide rates.[7,9]; (e) they used data from after the World War II (because only a small proportion of the population would have been exposed to the media at that time compared to the after-war period)[23]; and (f) met basic quality criteria, namely: (i) the presence of a clear definition of the "celebrity term" used in the study or a description of the celebrity analyzed; (ii) the adequate reporting of statistical procedures which would allow for the repetition of the analyses made when the original data were available; (iii) absence of any obvious flaws in the design or conduct of the study derivable from an in-depth reading of the relevant article. Editorials, comments and all other publications were excluded if they did not present primary or secondary data. Data on celebrity suicides that were reported in several studies were counted only once. This selection process yielded 10 studies. For an overview of process of study selection, see the flowchart presented at Figure 1.

\section{Data extraction}

The data extracted for each study were: (a) the name of the country where the study took place; (b) the publication year; (c) the mean population size across the observation period of the respective study; (d) the number of celebrity suicides that were analyzed;

(e) the type of celebrity, based on previously-developed taxonomy;[13] (f) the mean 
difference in suicide rate in the month before versus month after the media reporting; $(\mathrm{g})$ the standard error of the difference; and (h) a short description of the portrayed suicide(s).

For four studies which did not report the difference in suicide rates and the standard error of the difference[7,13,15,35], the data were obtained from authors. This was made easy by the fact that we shared co-authors in common (TN, KWF and SS, respectively).[7,9,13] Population sizes were obtained from relevant national statistical agencies if they were not stated in the particular study. All coders were familiar with the literature analyzed. JP, KW, KF, PY, and TN extracted the data independently using a piloted Excel template and compared the extracted data afterwards, reaching an agreement rate of $100 \%$.

\section{Quantitative data synthesis}

The effect estimates were the differences in monthly suicide rates between the month(s) when the respective celebrity suicide was reported and a reference period (preceding month(s). The effect estimates for all 10 studies were pooled to obtain a combined effect size. Initial data inspection indicated potential heterogeneity between studies, so random effects meta-analysis with restricted maximum likelihood estimation was used to estimate the summary statistics.[24]. I $^{2}$ statistics and Cochran's $Q$ test were used to estimate the amount of residual heterogeneity and to test for statistical significance, respectively.[25] Publication bias was visually assessed using a funnel plot, and quantitatively tested by rank correlation test,[26] and regression test for asymmetry.[27] 


\section{Sources of heterogeneity}

We used mixed-effects meta-regression to determine which factors might be contributing to the observed between-study variation. We examined five variables: region of study (North America [reference group], Asia, Australia, and Europe); decade of publication (2000-2009 [reference group] and 1980-99); number of celebrities investigated (an integer); population size (taking the year average within the observation period of the respective study); and type of celebrity with regard to professional group and national identity (national entertainment elite, foreign or less known celebrity, mixed sample [reference group]).

The region-specific and time-specific variables were included because it was thought that the socio-cultural circumstances associated with them might have an impact on the amount of copycat behaviour, $[5,29,30]$ and the way the term celebrity status is defined in a study may have an impact on any association with suicide rates. Definitions used to define celebrity status vary widely across studies on celebrity suicides and seem likely to be more inclusive of relatively less famous individuals in studies analyzing the associations of several celebrity suicides with suicide rates compared to studies dedicated to the analysis of the effect of one specific celebrity suicide.

The population size of the country where the study was conducted might help explain heterogeneity across study findings, because population size constitutes an indicator of the complexity of media structures in countries.[31] 
The type of celebrity was considered relevant based on a US-study which analyzing data on a large number of celebrities and found that only suicides by national elite entertainers were associated with increases in suicide rates in the population.[13] It has been suggested this finding may be explained by the perceived high social status of entertainers as compared with other famous persons (e.g., politicians) and the more pronounced social identification with individuals from the own country as compared to foreigners.[7,28]

The model was statistically adjusted by using Knapp and Hartung method to help control the risk of spurious findings.[32] The Variance Inflation Factor (VIF) was calculated to diagnose the model's multicollinearity. If its value is larger than 10 , this is an indicator of severe multicollinearity in the model.[33] The number of celebrities was strongly correlated with the year of publication (Pearson's $r=0.65$ ) and with population size $(r=0.63)$. The other study characteristics did not show multicollinearity.

We used R meta-analysis package metaphor to conduct all statistical analyses.[34]

\section{Ethics statement}

Review by a research ethics committee was not required for this work because of the use of published, aggregate data. The study was conducted in accordance with the Declaration of Helsinki. 


\section{RESULTS}

\section{Identification of studies}

Figure 1 shows how we arrived at the 10 studies that were included in the analysis. In total, we identified 102 studies on the association between media reporting of suicide and actual suicidal behaviour. Fifty five of these were ecological in nature, 49 of which used completed suicide as the outcome variable. From this sample, 16 studies focused on one or several celebrity suicides.[3,7,9,10,12-16,19,23,35-39] Of these, one study analyzed a specific suicide method but not total suicides.[37] One study reported on celebrity suicides that happened before 1930.[23] Four studies were replications that used the same data or a smaller amount of the same data which was also used in another identified study.[3,19,38,39] The remaining 10 studies were checked for basic quality criteria as outlined in the methods section. All 10 studies met these criteria and were eligible for the meta-analysis. $[7,9,10,12-16,35,36]$.

\section{Study characteristics}

Table 1 shows the characteristics of the 10 eligible studies. 
Table 1 - Study Characteristics

\begin{tabular}{|c|c|c|c|c|c|c|}
\hline $\begin{array}{l}\text { Eligible studies (listed in } \\
\text { alphabetical order) }\end{array}$ & $\begin{array}{c}\text { Year of } \\
\text { Publication }\end{array}$ & $\begin{array}{c}\text { Region of } \\
\text { Study }\end{array}$ & $\begin{array}{l}\text { No of } \\
\text { reported } \\
\text { celebrity } \\
\text { suicides }\end{array}$ & $\begin{array}{l}\text { Characteristics of } \\
\text { suicides }\end{array}$ & Type of celebrity & $\begin{array}{c}\text { Population } \\
\text { Size } \\
\text { (million) }{ }^{1}\end{array}$ \\
\hline
\end{tabular}

Chen et al. [35]

2010 Taiwan

1 Ivi Li, newcomer singer in Foreign or less known

22.9

Taiwan, killed herself by entertainer

burning charcoal on 13

November 2008 at the

age of 24.

Cheng et al. [15, see

2007

Taiwan also 9]

Mr. Min-Jan Nee,

National entertainment elite

television actor in

Taiwan, died by hanging

on May 2, 2005, at the age of 59 .

Fu and Yip [9]

2009 South Korea

1

South Korea's actress

National entertainment elite

48.01

Ms. Eun-ju Lee, died by

hanging on February 22,

2005 , at the age of 25 .

Jonas [10]

1992 Germany

32 Archival information from Mixed sample

German magazines

(1968-1980) using

search term "suicides of

prominent persons",

record on deceased

celebrities, media

presence in 5 years

before suicide, and

suicide publizised in at

least two newspapers.

Martin and Koo [12] ${ }^{2}$

$1997 \quad$ Australia

1 US singer of Nirvana KurtForeign or less known 


\begin{tabular}{|c|c|c|c|c|c|c|}
\hline & & & & $\begin{array}{l}\text { Cobain, shot himself on } \\
\text { April } 5 \text { 1994, at the age } \\
\text { of } 27 .\end{array}$ & entertainer & \\
\hline $\begin{array}{l}\text { Niederkrotenthaler et al. } \\
\text { [7] }\end{array}$ & 2009 & Austria & 16 & $\begin{array}{l}\text { "A celebrity" if the } \\
\text { individual satisfied both } \\
\text { conditions of (a) being } \\
\text { present in the media } \\
\text { before suicide, and (b) } \\
\text { belonging to the upper } \\
10 \% \text { of highest amount of } \\
\text { suicide reporting in the } \\
\text { sample, 1996-2006. }\end{array}$ & Mixed sample & 8.09 \\
\hline Queinec et al. [36] & 2011 & France & 6 & $\begin{array}{l}\text { Celebrity's name } \\
\text { appeared at least } \\
100,000 \text { times in pages } \\
\text { indexed in French using } \\
\text { the Google search } \\
\text { engine. Suicides occurred } \\
\text { between } 1979-2006 \text {. }\end{array}$ & Mixed sample & 57.3 \\
\hline Stack [13] & 1987 & United States & 38 & $\begin{array}{l}\text { Appeared in New York } \\
\text { Times annual indexes in } \\
\text { at least } 2 \text { of the } 5 \text { years } \\
\text { before his/her death, } \\
\text { 1948-1983. }\end{array}$ & Mixed sample & 192.80 \\
\hline Tousignant et al. [14] & 2005 & Canada & 1 & $\begin{array}{l}\text { Gaetan Girouard, a } \\
\text { television reporter in } \\
\text { Quebec, Canada, died by } \\
\text { hanging on } 14 \text { January } \\
1999 \text { at the age of } 33 \text {. }\end{array}$ & National entertainment elite & 7.34 \\
\hline
\end{tabular}

\begin{tabular}{lllll}
\hline Yip et al. [16, see also 9] 2006 & Hong Kong & 1 & $\begin{array}{l}\text { Mr. Leslie Cheung, Hong National entertainment elite } \\
\text { Kong singer and actor, }\end{array}$ & 6.77 \\
\hline
\end{tabular}


died by jumping from a height on April 1, 2003 at the age of 46.

${ }^{1}$ Mean population size in the observation period in the investigated region.

${ }^{2}$ This study restricted outcome measurement to the age group of 15 to 24 years. 
Four studies were conducted in Asian countries - Hong Kong,[16] Taiwan (2 studies),[15,35] South Korea [9] - and one in Australia [12]. Two studies were conducted in North America (United States [13] and Canada [14]). There were three European studies which were conducted in Austria,[7] Germany,[10] and France,[36] respectively. Four of the included studies investigated the effects of several celebrity suicides (ranging from six to 38 studied suicides), $[7,10,13,36]$ and six studies focused either on a single celebrity suicide.[12,14-16,35] or provided original data related to one specific celebrity suicide [9]. .. Seven papers were published between 2000 and $2009,[7,9,14-16,35,36]$ two were published in the $1990 \mathrm{~s},[10,12]$ and one was published in the1980s.[13]

\section{Quantitative data synthesis}

Figure 2 shows the forest plot. The random-effects summary estimate was $0.26(95 \% \mathrm{Cl}$ $0.09,0.43)$. The heterogeneity test indicated significant between-study variation $\left(I^{2}=91 \%\right.$; $\mathrm{Q}=66.8, P<0.0001)$.

Table 2 showes the results of the mixed-effects meta-regression model used to identify possible sources of heterogeneity. Type of celebrity (national entertainment elite) and region of study (Australia) were found to be statistically significant.

\section{Table 2 - Results of Mixed-Effects Meta-Regression Model}

\begin{tabular}{lccc} 
& Effect Estimate & $95 \% \mathrm{Cl}$ & $P$ \\
\hline Intercept $_{\text {National entertainment elite }}{ }^{1}$ & 0.09 & $-0.06,0.24$ & 0.14 \\
Foreign or less known $_{\text {entertainer }^{1}}$ & 0.55 & $0.37,0.72$ & $0.002^{\star \star}$ \\
& 0.06 & $-0.15,0.27$ & 0.43
\end{tabular}


Region of Study: Asia²

Region of Study: Australia²

Region of Study: Europe ${ }^{2}$

Year of Publication 1980-1999 ${ }^{3}$

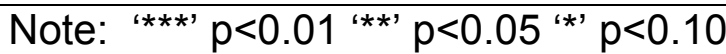

Test for residual heterogeneity: $\mathrm{QE}(\mathrm{df}=3)=0.40, P=0.94$

${ }^{1}$ Reference group is mixed samples.

${ }^{2}$ Reference group is region of study: North America

${ }^{3}$ Reference group is year of publication 2000-2009

The coefficients of other explanatory variables were not significant. The variables number of celebrities and population size were not used in the analysis because of strong multicollinearity in the resulting model, yielding inflated Variance Inflaction Factors. The heterogeneity test for the meta-regression model indicated no remaining statistically significant between-study variation $(\mathrm{QE}(\mathrm{df}=3)=0.40, P=0.94)$.

In summary, type of celebrity and region of study appeared to explain the observed heterogeneity. If a study of a national entertainment elite's suicide was published between 2000 to 2009, the effect was $0.64(95 \% \mathrm{Cl} 0.55,0.73)$ if the study was undertaken in the North America. If it was an Asian study, the effect size was estimated at $0.58(95 \% \mathrm{Cl} 0.47,0.68)$. If the study was conducted in Australia, the estimate was $0.36(95 \% \mathrm{Cl}-0.10,0.61)$ and if it was a European study, the estimate was $0.68(95 \%$ Cl 0.51, 0.85).

If a celebrity was foreign or less known to the public, the effect was estimated at 0.16 $(95 \% \mathrm{Cl} 0.01,0.31)$ for studies conducted in the North America and $0.09(95 \% \mathrm{Cl} 0.04$, 0.15) for Asian studies. For studies conducted in Australia and Europe, the coefficients were not statistically significant and estimated at $-0.13(95 \% \mathrm{Cl}-0.35,0.09)$ for Australian studies and $0.19(95 \% \mathrm{Cl}-0.01,0.40)$ for European studies, respectively. 
Figure 3 shows the funnel plot. The distribution of effect estimates seemed to be rather symmetrical, suggesting no direct evidence of publication bias. Both rank correlation test (Kendall's tau $=0.31, P=0.21)$ and regression test $(z=0.98, P=0.33)$ were not significant and supported this interpretation. 


\section{DISCUSSION}

This study provides novel cumulative insights into the asssociation between news stories about celebrity suicides and suicide rates. It summarizes the strength of the effects in the literature and contributes to the examination of variables that moderate the effect. The pooled estimate of the ten eligible studies on 98 celebrity suicides indicated an average increase in the suicide rate of $0.26(95 \% \mathrm{Cl} 0.09,0.43)$ in the month after a report on a celebrity suicide. There was substantial heterogeneity between studies. Mixed meta-regression indicated that this heterogeneity could be explained by the continent where the study was conducted, and by the type of celebrity whose suicide was reported. Effects were most pronounced after reports on suicide by national top entertainers. There appeared to be no publication bias as indicated by a funnel plot and related statistical tests.

The finding that study heterogeneity was partially explained by the study region may indicate differences in reporting practices and quality across regions. Previous research showed that reporting quality varied from country to country.[30] This variation was considered to reflect differences in cultural attitudes and values towards suicide [30] The finding that effect sizes for studies on national top entertainers were higher than for other celebrity groups is consistent with earlier literature which identified suicides by national top entertainers to be most consistently associated with post-report increases in suicide rates.[5,13] The high social status of national top entertainers as compared to other celebrity types, and the greater potential of identification with celebrities from one's own country as compared to foreign celebrities may contribute to this finding.[,28].The 
lack of any direct indication of publication bias is also noteworthy. Concerns about selective publication of positive findings related to effects of celebrity suicide reporting have been raised in earlier related literature [21].

\section{Strengths and limitations}

The main strength of the present analysis is the extensive and systematic literature review which used a wide set of search terms and databases. This is likely to have exhaustively identified studies in the topic area. A further strength is the independent extraction of data from the studies by several individuals, which resulted in complete agreement concerning the data used for the analysis. Further, the selection of studies that met predefined quality criteria resulted in the inclusion of studies with acceptable quality.

This study also has limitations. Like the primary studies included in this review, this meta-analysis could only identify temporal associations, and could not establish causality.[40] Furthermore, our emphasis on celebrity suicides meant that only ten studies were eligible for inclusion, which had implications for the statistical power of the analysis. We justified this restriction on the grounds that celebrity suicides are the most likely to be reported and to have the largest impact on suicide rates, but it influenced the level of precision of our results..

\section{Implications for research and public health practice}


Further research is needed to investigate the potential impact of study region on copycat behaviour. In particular, studies investigating international differences in the quality of suicide reportining and the association between regional reporting quality and suicide rates are needed. The present study also indicates that more uniform approaches to study design and definitional issues are necessary to facilitate a comparison of studies.

This meta-analysis has clear public health implications. It confirms that particular caution is necessary when reporting suicides by celebrities. Celebrity suicides will always be reported because they are particularly newsworthy, and we are not suggesting that they be censored. Instead, we would argue that they should be reported in a responsible manner in view of the existing results. There are vulnearble individuals in the community who would be affected. This recommendation is consistent with international guidelines on media reporting of suicide. Public health professionals (particularly those working in the areas of mental health promotion and suicide prevention) should collaborate with media professionals to make sure that reporting minimizes the risk of copycat acts.[17] 


\section{ACKNOWLEDGEMENTS}

The authors would like to thank the many useful suggestions from the reviewers and the work occurred as a result of a collaboration between members of the International Association for Suicide Prevention's Suicide and the Media Task Force'.

None.

\section{COMPETING INTEREST}

Non declared.

\section{FUNDING}

This work was supported by the Faculty of Social Science of the University of Hong Kong and a GRF grant (HKU 784210M) and benefited from a working meeting held in Hong Kong in 2010. The funding bodies had no role in study design, data collection and analysis, decision to publish, or preparation of the manuscript.

\section{LICENCE FOR PUBLICATION}

The Corresponding Author has the right to grant on behalf of all authors and does grant on behalf of all authors, an exclusive licence (or non exclusive for government employees) on a worldwide basis to the BMJ Publishing Group Ltd to permit this article (if accepted) to be published in JECH and any other BMJPGL products and sublicences 
such use and exploit all subsidiary rights, as set out in our licence

(http://group.bmj.com/products/journals/instructions-for-authors/licence-forms).

WHAT THIS STUDY ADDS

What is already known on this subject?

- Reporting of celebrity suicides has repeatedly been found to be followed by increases in suicides.

- However, the topic has remained controversial because of some negative findings.

\section{What this study adds?}

- Bringing together the data from individual studies in different countries into a single meta-analysis allows us to conclude that celebrity suicide is associated with increases in subsequent suicides.

- The effect size appears to depend on the country where the study is conducted and on the type of celebrity.

- Cautious reporting on celebrity suicide is necessary. 


\section{REFERENCES}

1. Hawton K, van Heeringen K. Suicide. Lancet 2009;373:1372-1381.

2. Mann JJ, Alan A, Bertolote J, et al. Suicide prevention strategies - A systematic review. JAMA 2005;294:2064-2074.

3. Phillips DP. The influence of suggestion on suicide: Substantive and theoretical implications of the Werther effect. Am Soc Rev 1974;39:240-253.

4. Pirkis J, Blood W. Suicide and the media. Part II: Reportage in nonfictional media. Crisis $2001 ; 22: 146-154$.

5. Stack S. Suicide in the media: A quantitative review of studies based on nonfictional stories. Suicide Life Threat Behav 2005;35:121-133.

6. Pirkis JE, Burgess PM, Francis $\mathrm{C}$, et al. The relationship between media reporting of suicide and actual suicide in Australia. Soc Sci Med 2006;62:2874-2886.

7. Niederkrotenthaler T, Till B, Voracek M, et al. Copycat effects after media reports on suicide: A population-based study. Soc Sci Med 2009;69:1085-1090. 
8. Niederkrotenthaler T, Voracek M, Herberth A, et al. The role of media reports in completed and prevented suicide-Werther versus Papageno effects. $\mathrm{Br} \mathrm{J}$ Psychiatr 2010;197:234-243.

9. Fu KW, Yip PS. Estimating the risk for suicide following the suicide deaths of three Asian entertainment celebrities: A meta-analysis approach. J Clin Psychiatry 2009;70:869-878.

10. Jonas K. Modelling and suicide: a test of the Werther effect. Br J Soc Psychol 1992;31:295-306.

11. Pirkis J, Blood W. Suicide and the media. Part III: Theoretical issues. Crisis 2001;22:163-169.

12. Martin G, Koo L. Celebrity suicide: Did the death of Kurt Cobain influence young suicides in Australia? Arch Suicide Res 1997;3:187-198.

13. Stack S. Celebrities and suicide: A taxonomy and analysis, 1948-1983. Am Sociol Rev 1987;52:401-412.

14. Tousignant M, Mishara BL, Caillaud A, et al. The impact of media coverage of the suicide of a well-known Quebec reporter: the case of Gaetan Girouard. Soc Sci Med 2005;60:1919-1926. 
15. Cheng ATA, Hawton K, Lee C, et al. The influence of media reporting of the suicide of a celebrity on suicide rates: A population-based study. Int J Epidemiol 2007;36:1229-1234.

16. Yip P, Fu KW, Yang KCT, et al. The effects of a celebrity suicide on suicide rates in Hong Kong. J Affect Disord 2006;93:245-252.

17. World Health Organisation. Preventing suicide. A ressource for media professionals. Geneva; 2008. (http://www.who.int/mental_health/prevention/suicide/resource_media.pdf). (Accessed October 22, 2011).

18. Mercy JA, Kresnow MJ, O'Carroll PW, et al. Is suicide contagious? A study of the relation between exposure to the suicidal behaviour of others and nearly lethal suicide attempts. Am J Epidemiol 2001;154:120-127.

19. Hittner J. How robust is the Werther effect? A re-examination of the suggestion-imitation model of suicide. Mortality 2005;10:193-200.

20. Pirkis J, Blood W. Suicide and the news and information media: a critical review. Mindframe; 2010. (http://www.mindframe-media.info/client images/900016.pdf). (Accessed October 22, 2011). 
21. Sisask M, Värnik A. Media roles in suicide prevention; a systematic review. Int J Environ Res Public Health 2012:9:123-138

22. Oxford Centre for Evidence-based Medicine. Levels of Evidence. Oxford; 2010. (http://www.cebm.net/index.aspx?o=1047). (Accessed October 22, 2011).

23. Stack S. The effect of the media on suicide: The Great Depression. Suicide Life Threat Behav 1992;22:255-267.

24. Borenstein M. Introduction to meta-analysis. Chichester, U.K.: John Wiley \& Sons 2009.

25. Higgins JPT, Thompson SG, Deeks JJ, et al. Measuring inconsistency in metaanalyses. BMJ 2003;327:557-560.

26. Begg C, Mazumdar M. Operating characteristics of a rank correlation test for publication bias. Biometrics 1994;50:1088-1101.

27. Egger M, Smith G, Schneider M, Minder C. Bias in meta-analysis detected by a simple, graphical test. BMJ 1997;315:629-634.

28. Marger M. Elites and Masses. New York: D. Van Nostrand 1981. 
29. Stack S. Social correlates of suicide by age. Media impacts. In: Leenaars, AA, ed. Life span perspectives of suicide. Time lines in the suicidal process. New York: Plenum Publishing 1992:187-214.

30. Fekete S, Schmidtke A, Takahashi Y, et al. Mass media, cultural attitudes, and suicide: an international comparative study. Crisis 2001;22:170-172.

31. Färdigh MA. Comparing Media Systems in Europe: Identifying Comparable Country level Dimensions of Media Systems. Gothenburg: University of Gothenburg ; 2010. (http://www.qog.pol.gu.se/working papers/2010 2 Fardigh.pdf).(Accessed October 22, 2011).

32. Knapp G, Hartung J. Improved tests for a random effects meta regression with a single covariate. Stat Med 2003;22:2693-2710.

33. Kleinbaum DG, Kupper LL, Muller KE. Applied regression analysis and other multivariable methods. Boston, Mass: PWS-Kent Pub \& Co 1988.

34. Viechtbauer W. Conducting meta-analyses in $\mathrm{R}$ with the metafor package. Journal of Statistical Software 2010;36:1-48.

35. Chen YY, Liao SF, Teng PR, et al. The impact of media reporting of the suicide of a singer on suicide rates in Taiwan. Soc Psychiatry Psychiatr Epidemiol 2010;45:363-369. 
36. Queinec R, Beitz C, Contrand B, et al. Copycat effect after celebrity suicides: results from the French national death register. Psychol Med 2011;41:668-671.

37. Etzersdorfer E, Voracek M, Sonneck G. A dose-response relationship of imitational suicides with newspaper distribution. Aust N Z J Psychiatr 2001;35:251.

38. Wasserman IM. Imitation and suicide: A re-examination of the Werther effect. Am Sociol Rev 1984;49:427-436.

39. Stack S. A Reanalysis of the Impact of Non-Celebrity Suicides - a Research Note. Soc Psychiatry Psychiatr Epidemiol 1990;25:269-273.

40. Cooper $\mathrm{H}$, Patall EA. The relative benefits of meta-analysis conducted with individual participant versus aggregated data. Psychol Methods 2009;14:165-176. 


\section{Figure legends}

Figure 1: Literature research flowchart. Abbreviations: No Number.

Figure 2: Forest plot of effect sizes, i.e. changes in suicide rates per 100,000 population in month after celebrity suicide, and $95 \%$ confidence intervals from 10 included studies that assessed the influence of celebrity suicide on suicide rate in the community. The pooled random-effects estimate and the corresponding 95\% confidence interval are also shown at the bottom.

Figure 3: Funnel plot of the observed outcomes in ten studies on the association of celebrity suicide reporting with actual suicide rates. Each dot represents a different study. 